\title{
KESANTUNAN BERBAHASA INDONESIA SISWA SEKOLAH DASAR NEGERI O6 KOTA BENGKULU
}

\author{
Daimun Hambali \\ Universitas Bengkulu \\ Novia \\ Universitas Bengkulu
}

\begin{abstract}
The purpose of this study was to describe the politeness of Indonesian between students and between students and teachers at SDN 06 Bengkulu City neighborhood. The research subject is that students of class $V$. The scope of this research is the use of verbal and nonverbal politeness by students at SDN 06 Bengkulu: students with students, and students with teachers. This type of research is qualitative descriptive. Data collected by observation, field notes, interview techniques and recording technique. Steps of data analysis conducted in stages, data reduction, data display and data verification. Results of research on linguistic politeness Indonesia students in the SDN 06 Bengkulu city, namely (1) for politeness the studentsdata found conversational politeness students more than the data conversation violation of politeness that is, 21 data is conversations that contain maxims of politeness and 5 the data conversation violation maxim of politeness, (2) for politeness between students and teachers found 7 data containing politeness conversation, and was not found students who violate the maxim of politeness and not found students against teachers. All data that conversation concluded with a look at the context of the speech that underlie the events said. The conclusion from this study is that politeness between students and between students and teachers reveal politeness. For nonverbal language, in speaking students use the fit between body language and speech (verbal).
\end{abstract}

Keywords: Politeness, Verbal Language, Nonverbal Language, Elementary Students

\section{PENDAHULUAN}

Manusia sebagai makhluk sosial memerlukan berkomunikasi kepada orang lain. Dalam berkomunikasi seseorangmemerlukan sarana untuk menyampaikan pesan. Salah satu bentuk sarana yang dapat digunakan adalah bahasa. "Bahasa adalah sistem lambang bunyi arbitrer yang dipergunakan dalam kehidupanbermasyarakat untuk bekerja sama, berinteraksi, dan mengidentifikasi diri" (Aslinda, 2007: 1).

Pranowo (2009: 3) menyatakan, bahwa bahasa merupakan cermin kepribadian seseorang, bahkan lebih luas lagi, bahwa bahasa adalahsebagai cermin kepribadian bangsa. Artinya, melalui bahasa seseorang atau suatu bangsa dapat diketahui kepribadiannya.
Bangsa Indonesia memiliki berbagai ragam bahasa, suku, dan budaya.Terkait dengan bahasa, di Indonesia terdapat banyak bahasa daerah yang dipergunakan sebagai alat komunikasi oleh berbagai suku dan sekaligus sebagai khasanah kekayaan bangsa.

Ricour dalam Wibowo (2015: 13), menyatakan, bahwa bahasa selalu untuk mengatakan sesuatu yang dibaluti oleh nilai-nilai etis atau kesantunan. Sehingga, bahasa yang santun merupakan alat yang paling bermartabat digunakan dalam berkomunikasi dan menjalin hubungan sosial. Karena bahasa santun memperhatikan kaidah kebahasaan dan tatanan nilai yang berlaku di dalam masyarakat pemakainya.

Pemakaian bahasa yang santun, pada hakikatnya digunakandengan tujuan agar petutur dan petutur tidak merasa tertekan, tersudut, atau 
tersinggung Bahasa yang santun digunakan dalam interaksi antarmanusia dengan baik dan konsisten akan menciptakan suatu kondisi yang damai, tenang, dan harmonis(Markhamah, 2009: 153). Untuk mewujudkan kondisi tersebut, perlu adanya usaha pelestarian dan pewarisan budaya berbahasa santun di masa depan. Salah satu usaha terletak pada generasi muda sebagai pengguna bahasa saat ini.

Secararealitas melalui obsevasike sekolah dasar negeri (SDN) 06 Kota Bengkulu, peneliti mengamati adanya kecenderungan siswamenggunaan bahasa yang kuranag santun. Sebagai contoh, terjadituturan saling olokmengolok antarsiswa. Siswa sudah berani membentak guru, siswa yang bersikap tidak sopan sesamanya, dan siswa melawan guru memalui tuturannya. Bahkan, ada siswa yang berani tawuran akibat komunikasi yang tidak santun (saling mengejek). Hal ini sesuai dengan Maharani (2014: 77), bahwa keadaan yang memprihatinkan di sekolah adanyaketidaksantunan bahasa yang dituturkan siswa di dalam pembelajaran,baik kepada guru maupun kepada siswa yang lain.

Untuk mengantisipasi keadaan bertutur yang kurang santun seperti yang telah dikemukakan di atas, maka berbagai pihakmulai dari keluarga, guru, penyelenggara sekolah,maupunmasyarakatsupaya memberi contoh cara bertutur yang santun.Karena berbahasa yang santun harus ditanamkan sedini mungkin. Anak-anak atau siswa di sekolah perlu dilatih dan dibiasakan untuk menggunakan bahasa yang santun ketika berbicara.

Apabila dikaitkan dengan berbahasa santun di sekolah, maka kesantunan berbahasa erat hubungannya dengan pembelajaran bahasa Indonesia. Dalam pembelajaran bahasa, satu sarana yang tepat utuk digunakan melatih siswa dalamberbahasa yang santun. Walaupun, tugas melatih dan mencontohkan berbahasa yang santun tidak hanya terletak pada guru bahasa Indonesia di sekolah.

Abidin (2013: 15) menyatakan, bahwa berdasarkan tujuan pembelajaran bahasa Indonesia, berkomunikasi secara efektif dan efesien harus sesuai dengan etika. Sehingga apabila tujuan ini tercapai, maka tidak akan ada kegaduhan antarsiswa ketika sedang berkomunikasi. Oleh karena itu, bertutur yang santun sesuai etika perlu dilatih dan dibiasakan oleh seluruh guru dan berikut seluruh siswa di sekolah.

Sauri (2006: 132),juga menyatakan, bahwa upaya menanamkan kesantunan berbahasa selaras dengan tujuan pendidikan umum, yakni mempersiapkan pesertadidik agar mampu berkomunikasi. Akan tetapi, pendidikan berbahasasantun bukan hanya mengarahkan atau menyentuh ranah kognitif, melainkan membina ranah afektif dan psikomotorik secara keseluruhan. Oleh karena itu, output pendidikan umum bukanlah manusiayang ahli dalam berbahasa saja, tetapi juga manusia yang mampu berkomunikasi denganbaik dan benar serta santun.

Dalam bahasa santun tidak hanya mengarah pada penggunaan bahasa verbal atau ucapan saja, tetapi juga mengaitkanya dengan bahasa nonverbal. Menurut Mehrabian dalam Cangara (2012: 117), tingkat kepercayaan dari pembicaraan orang hanya 7 persen berasal dari bahasa verbal, 38 persen dari vokal suara, dan 55 persen dari ekspresi muka. Oleh sebab itu, bahasa nonverbal juga ikut andil dalam penggunaan bahasa yang santun, karena bahasa verbal tidak dapat dipercaya begitu saja tanpa memperhatikan bahasa nonverbal yang digunakan.

Dalam penelitian ini, diawali dengan observasi ke sekolah dasar sasaran, untuk melihat ada tidaknya relevansi penelitian kesantunan berbahasa pada siswa. Penelitian terkait dengan kesantunan berbahasa tingkat SMP telah dilakukan oleh Puspa Rinda Silalahi (2012), yaitu "Analisis Kesantunan Berbahasa Siswa di Lingkungan Sekolah SMP Negeri 5 Binjai."Dalam penelitianya, kesantunan berbahasa siswa sudah dapat dikatakan cukup santun karena dari hasil penelitianya ditemukan tuturan yang memenuhi prinsip kesantunan berbahasa Leech lebih banyak dibandingkan dengan yang melanggar prinsip kesantunan berbahasa. 
Kemudian jurnal pendidikan Ling Tera oleh Astiana Ajeng Rahadini (2014) mengenai "Kesantunan Berbahasa dalam Interaksi Pembelajaran Bahasa Jawa di SMPN 1 Banyumas". Adapun hasil penelitiannya adalah nilai kesantunan berbahasa dalam interaksipembelajaran bahasa Jawa di SMP N 1Banyumas dilihat dari isi tuturan guru dan siswamematuhi prinsip kebijaksanaan, prinsipformalitastepa selira, prinsip penghargaan dankerendahan hatiandhap asor, dan prinsip ketidaklangsungan.

Untuk penelitian ini, lokasi yang dipilih peneliti pilih adalah SDN 06 Kota Bengkulu. Hasil observasi awalditemukan banyak siswa yang berbicara tidak sesuai dengan prinsipprinsip kesantunan berbahasa. Selain itu, tingkat kesantunan berbahasa siswa terhadap guru juga masih rendah. Hal ini dibuktikan dengan ditemukannya tuturan siswa yang tidak santun, seperti tuturan ketika membentak dan melawan guru. Untuk itulah, perludilakukan penelitian kesantunan berbahasa di sekolah ini. Berdasarkan latar belakang yang telah peneliti paparkan, maka judul yang diangkat dalam penelitian iniadalah Kesantunan Berbahasa Indonesia Siswa Sekolah Dasar Negeri 06 Kota Bengkulu.

Berdasarkan latar belakang di atas, maka rumusan masalah penelitian ini adalah:(1) Bagaimana kesantunan berbahasa Indonesia antarsiswa pada SDN 06 Kota Bengkulu? dan(2) Bagaimana kesantunan berbahasa Indonesia antara siswa dengan guru pada SDN 06 Kota Bengkulu?

\section{METODE}

Jenis penelitian ini adalah deskriptifkualitatif. Sugiyono (2014: 7) menyatakan, bahwa metode kualitatif disebut juga sebagai metode artistik. Dikatakan sebagai metode artistik karenaproses penelitian lebih bersifat seni (kurang terpola), dan disebut jugasebagai metode interpretative karena data hasil penelitian lebihberkenaan dengan interprestasi terhadap data yang ditemukan di lapangan.Menurut Winarni, (2011: 38) penelitian deskriptif diarahkan untuk mencari gejalagejala, fakta-fakta, kejadian-kejadian secara sistematis dan akurat mengenai sifat-sifat populasi atau daerah tertentu.

Penelitian kualitatif mencari makna kontekstual secara menyeluruh (holistic) berdasarkan fakta-fakta (tindakan, ucapan, sikap, dsb) yang dilakukan subjek penelitian dalam latar alamiah (Hanafi, 2011: 92. Peneliti memberikan gambaran secara objektif tentang penggunaan kesantunan berbahasa Indonesia siswa di sekolah dasar berdasarkan teori-teori kebahasaan, yaitu teori kesantunan berbahasa Leech dan Dell Hymes.

Subjek penelitian ini adalah siswa kelas V di SDN 06 Kota Bengkulu. Dalam penelitian ini ada dua bentuk data yang dikumpulkan, yaitu data primer dan data sekunder. Mukhtar (2013: 100) menyatakan bahwa data primer adalah yang dihimpun langsung oleh peneliti. Data ini dikumpulkan dari hasil observasi terhadap situasi sosial atau diperoleh dari tangan pertama (informan).Sehingga, data primer merupakan data yang didapatkan langsung dari subjek utama penelitian. Dalam penelitian ini data primernya adalah tuturan dan tindakan (bahasa tubuh) siswa.

Data sekunder merupakan data yang sifatnya sebagai pendukung atau pelengkap terhadap data primer. Data sekunder diperoleh secara tidak langsung oleh peneliti, tapi melalui sumber tangan kedua atau ketiga. Data sekunder dalam penelitian ini adalah informasi atau hasil jawaban dari pertanyaan-pertanyaan yang diajukan oleh peneliti kepada informan yang digunakan sebagai alat pengecekan untuk keabsahan data. Oleh karena itu, data sekunder dalam penelitian ini diperoleh melalui wawancara. Hasil wawancara tersebut peneliti gunakan untuk mendukung data observasi dan catatan lapangan.

Sumber data dalam penelitian ini adalah observasi kesantunan berbahasa dalam bentuk tuturan dan tindakan siswa. Kemudian guru kelasdan guru-guru yang mengajar mata pelajaran di luar mata pelajaran bahasa Indonesia di kelas $\mathrm{V}$ bertindak sebagai informan atau 
responden, yang merespon atau menjawab pertanyaan-pertanyaan yang diajukan oleh peneliti.

Pengumpulan data dilakukan pada natural setting(kondisi alamiah), sumber data primer dan teknik pengumpulan data lebih banyak pada observasi, wawancara,dan dokumentasi (Sugiyono, 2014: 225). Sehubungan dengan itu, maka teknik pengumpulan data menggunakan observasi, catatan lapangan, wawancara,dan teknik rekam.

\section{Pengamatan (Observasi)}

Teknik observasi menuntut adanya pengamatan dari peneliti baik secara langsung dan tidak langsung terhadap objek penelitian. Instrumen yang dipakai dapat berupa lembar pengamatan, panduan pengamatan dan lainnya (Umar, 2009:51). Sedangkan menurut Winarni (2011:148) observasi merupakan metode pengumpulan data yang menggunakan pengamatan terhadap objek penelitian. Observasi dapat dilaksanakan secara langsung maupun tidak langsung.

Observasi atau pengamatan yang digunakan dalam penelitian ini adalah observasi non-partisipatif (nonparticipatoryobservation). Seperti yang diungkapkan Sukmadinata (2010: 220) dalam observasi non-partisipatif, pengamat tidak ikut serta dalam kegiatan, dia hanya berperan mengamati kegiatan.

Dalam penelitian ini, pengumpulan data melalui observasi dilakukan oleh peneliti dengan tidak terlibat aktif di dalam kegiatan. Peneliti hanya mengamati proses kegiatan siswa di dalam ataupun di luar kelas. Penelitian ini memerlukan pedoman observasi (observation guide) yang digunakan untuk mengetahui penggunaan kesantunan berbahasa siswa di SDN 06 Kota Bengkulu. Peneliti mendalami danmengamati interaksi komunikasi yang terjadi, baik antarsiswa dan antara siswa dengan guruketika berkomunikasi di dalam maupun di luar kelas.

\section{Catatan Lapangan}

Dalam penelitian kualitatif, catatan lapangan adalah merupakan alat untuk melengkapi data utama, yang kemungkinan ada data tidak terduga baik saat dilakukan tuturan atau tindakan, tapi data tersebut dapat dilihat, dialami, dan dipikirkan dalam rangka pengumpulan data (Satori, 2013: 176). . Dalam penelitian ini catatan lapangan digunakan sebagai teknik pengumpulan data utama yang mendukung kegiatan observasi. Peneliti akan menggunakan catatan lapangan untuk mencatat semua tuturan siswa kelas V ketika berada di SDN 06 Kota Bengkulu, baik verbal maupun nonverbal yang berkaitan dengan kesantunan berbahasa.

\section{Wawancara}

Menurut Umar (2009:51) wawancara adalah salah satu teknik pengumpulan data yang pelaksanaannya dapat dilakukan secara langsung berhadapan dengan yang diwawancarai, tetapi juga secara tidak langsung seperti memberikan daftar pertanyaan untuk dijawab pada kesempatan lain.

Dalam wawancara biasanya terjadi tanya jawab sepihak yang dilakukan secara sistematis dan berpijak pada tujuan penelitian (Winarni, 2011: 132-133). Dalam penelitian ini, teknik wawancara yang dilakukan adalah wawancara terstruktur (structured interview), yaitu wawancara yang digunakan sebagai teknik pengumpulan data dan pengecekan data. Oleh karena itu dalam melakukan wawancara, peneliti telah menyiapkan instrumen penelitian berupa pertanyaan-pertanyaan tertulis.

\section{Teknik Rekam}

Teknik rekam merupakan salah satu teknik lanjutan yang ada dalam pengumpulan data linguistik atau kebahasaan (Sudaryanto, 1988: 2). Kemudian menurut Sutopo (2015), "rekaman video merupakan salah satu dari teknik pengumpulan data kualitatif, dalam penelitian sering dibuat rekaman video untuk melengkapi data". Oleh sebab itu, rekaman video dapat digunakan untuk menggali lagi data lebih dalam pada saat pengolahan data dilakukan.

Teknik analisis data dalam penelitian kualitatif belum ada pola yang jelas. Belum ada panduan untuk menganalisis data. Sugiyono ( 2014: 244) menyatakan bahwa analisis data merupakan proses mencari dan menyusun secara 
sistematis data yang diperoleh dari hasil wawancara, catatan lapangan, dan dokumentasi.

Adapun dalam penelitian ini, analisis data dimulai dengan menelaah seluruh data yang tersedia dari berbagai sumber, yaitu dari hasil pengamatan (observasi) yang berupa jawaban dari pedoman observasi, catatan lapangan dan rekaman, serta dari hasil wawancara yang sudah dicatat. Kemudian peneliti melakukan reduksi data. Langkah analisis selanjutnya adalah penyajian (display) data. Penyajian data adalah usaha merangkai informasi yang terorganisir dalam upaya menggambarkan kesimpulan dan mengambil tindakan. Penyajian data diarahkan agar data hasil reduksi terorganisasikan, tersusun dalam pola hubungan, sehingga makin mudah dipahami. Penyajian data pada penelitian ini dalam bentuk uraian deskriptif.Langkah berikutnya dalam proses analisis data kualitatif adalah menarik kesimpulan berdasarkan temuan dan melakukan verifikasi data, yaitu untuk mendapatkan bukti-bukti.

\section{HASIL DAN PEMBAHASAN}

Peneliti menguraikan hasil penelitian dan membahas tentang kesantunan berbahasa Indonesia siswa berdasarkan prinsip kesantunan berbahasa, baik kesantunan berbahasa verbal maupun nonverbal. Dalam penelitian kesantunan berbahasa Indonesia di lingkungan SDN 06 Kota Bengkulu, peneliti menemukan bahasa yang digunakan siswa ketika sedang berkomunikasi masih menggunakan bahasa ibu, yaitu bahasa Indonesia yang tidak baku bercampur dengan bahasa Melayu Bengkulu.

Ketika berkomunikasi, jarang ditemukan siswa berbicara menggunakan bahasa Indonesia sesuai dengan kaiadah yang benar, hanya ada beberapa siswa yang menggunakan bahasa Indonesia. Oleh karena itu, di dalam hasil ini, peneliti menerjemahkan percakapan siswa yang menggunakan bahasa ibu tersebut menjadi bahasa Indonesia.

Berkaitan dengan kesantunan berbahasa siswa, ditemukan 33 data percakapan yang dijadikan data dalam penelitian. Data percakapan kesantunan berbahasa antarsiswa di lingkungan
SDN 06 Kota Bengkulu terdiri dari 21 data percakapan, yang mencakup dalam keenam maksim kesantunan berbahasa Leech (1983), yakni (1) kebijaksanaan, (2) kedermawanan, (3) pujian, (4) kerendahan hati, (5) kesepakatan, dan (6) kesimpatian.

Kemudian untuk kesantunan berbahasa antara siswa dengan guru di lingkungan SDN 06 Kota Bengkulu terdiri dari 7 data percakapan, yang mencakup dalam dua maksim, yaitu (1) kebijaksanaan, dan (2) kesepakatan. Selain itu, dalam penelitian ini ditemukan juga 5 data percakapan yang melanggar prinsip kesantunan berbahasa, yakni melanggar maksim kebijaksanaan, maksim pujian, dan maksim kerendahan hati.

Sementara itu, untuk kesantunan bahasa nonverbal siswa, tidak banyak ditemukan pelanggaran terhadap fungsi komunikasi dan indikator dari kesantunan berbahasa nonverbal. Di dalam percakapan, siswa menggunakan bahasa tubuh dan bahasa isyarat sesuai dengan apa yang dituturkan.

Untuk kesantunan berbahasa antarsiswa, maksim yang paling banyak digunakan adalah maksim pujian, yaitu 5 maksim, sedangkan kesantunan berbahasa antara siswa dan guru hanya ditemukan 2 maksim, yaitu maksim kebijaksanaan dan maksim kesepakatan. Maksim kesantunan berbahasa antara siswa dengan guru yang paling banyak digunakan yaitu maksim kesepakatan.

Kemudian ditemukan pelanggaran kesantunan berbahasa siswa. Pelanggaran kesantunan ini hanya ditemukan antarsiswa saja.Pelanggaran kesantunan berbahasa antara siswa dan guru tidak ditemukan. Terdapat 3 pelanggaran kesantunan berbahasa, yakni (1) pelanggaran maksim kebijaksanaan, (2) pelanggaran maksim pujian, dan (3) pelanggaran maksim kerendahan hati. Pelanggaran kesantunan berbahasa paling banyak ditemukan adalah pelanggaran maksim pujian. 


\section{SIMPULAN}

Berdasarkan hasil penelitian dan pembahasan dapat disimpulkan sebagai berikut ini.

1. Tuturan berbahasa Indonesia antarsiswa menampakan kesantunan, karena dalam bahasa verbal ditemukan data percakapan santun lebih banyak dari data percakapan yang melanggar kesantunan berbahasa. Hal ini terlihat dari 21 data percakapan santun dan 5 data percakapan yang tidak santun. Untuk bahasa nonverbal, siswa sudah menerapkannya sesuai dengan bahasa verbal, dan tidak ditemukan tindak berbahasa yang menggunakan fungsi komunikasi kontradiksi antarsiswa.

2. Kesantunan berbahasa antara siswa dengan guru cukup santun, didapatkan 7 data percakapan siswa dengan guru yang menerapkan kesantunan berbahasa verbal, yaitu mengandung maksim kebijaksanaan dan maksim kesepakatan. Untuk bahasa nonverbal yang digunakan siswa sejalan dengan bahasa verbal, karena tidak ditemukan percakapan yang kasar dan tindakan siswa yang melawan guru selama masa penelitian.

\section{SARAN}

Berdasarkan hasil dan kesimpulan, disarankan sebagai berikutini.

1. Guru sebaiknya ikut berperan serta, dalam menanamkan kesantunan berbahasa pada saat proses pembelajaran ataupun di luar jam pembelajaran.

2. Kesantunan berbahasa Indonesia siswa di lingkungan SDN 06 Kota Bengkulu ialah suatu kajian yang menarik untuk diteliti karena membahas kesantunan bahasa yang digunakan oleh siswa di dalam lingkungan sekolah. Namun, dalam hal ini, peneliti menyadari bahwa penelitian tentang kesantunan berbahasa Indonesia siswa masih belum lengkap karena masih minimnya siswa yang menggunakan bahasa Indonesia sesuai dengan kaidah yang baik dan benar. Oleh sebab itu, penelitian ini masih terbuka untuk diadakan penelitian lebih lanjut.

\section{DAFTAR PUSTAKA}

Abidin, Yunus. 2013. Pembelajaran Bahasa Berbasis Pendidikan Karakter. Bandung: Refika Aditama.

Aslinda. 2007. Pengantar Sosiolinguistik. Bandung: Refika Aditama.

Cangara, Hafied. 2012. Pengantar Ilmu Komunikasi. Jakarta: Raja Grafindo Persada.

Hanafi, Halim Abdul. 2011. Metodelogi Pendidikan Bahasa.Jakarta: Diadit Media Press.

Leech, Geoffrey N. 1983. Principles of Pragmatics. London: Longman

Maharani, Wahju. 2014. Ketidaksantunan Berbahasa di Lingkungan Sekolah. Prosiding Seminar. Vol. 1, No.2, halm. 77

Markhamah, dkk. 2009. Analisis Kesalahan dan Kesantunan Berbahasa. Surakarta: Muhammadiyah Universitas Press.

Mislikha, 2014. "Kesantunan Berbahasa". International Journal of Islamic Studies Vol. 1, No.2, halm. 289-291.

Pranowo, 2009. Berbahasa Santun. Yogyakarta: Pustaka Belajar.

Purwanto, Ngalim. 2007. Ilmu Pendidikan Teoretis dan Praktis. Bandung. PT Remaja Rosdakarya.

Sauri, Sofyan. 2006. Pendidikan Berbahasa Santun. Bandung: PT.Gesindo.Sudaryanto, 1988. Metode Linguistik. Yogyakarta: Gadja Mada University Press

Sugiyono, 2014. Metode Penelitian Kuantitatif, Kualitatif dan $R \& D$. Bandung: Alfabeta.

Umar, Husein. 2009. Metode Penelitian untuk Skripsi dan Tesis Bisnis. Jakarta: Rajawali Pers. 
Wibowo, Wahyu. 2015. Konsep Tindak Tutur Komunikasi. Jakarta: PT. Bumi Aksara.

Winarni, Endang Widi. 2011. Penelitian Pendidikan. Bengkulu: Unit Penerbitan FKIP UNIB.

Sumber Penunjang:

Handoko, 2009. Menjadi Guru Yang Berwibawa dan Suri Tauladan. https://kangiwan19.wordpress.com/sikapmengajar-guru-serta-pengaruh-dalampendidikan/. Diakses oleh Novia, 27 Mei 2016 Pukul 10.17

Sutopo, Hadi. 2015. Teknik Pengumpulan dan Analisis DataKualitatif. http://www.pengertianpakar.com/2015/05/ teknik-pengumpulan-dan-analisisdata.html\#_. Diakses oleh Novia, 11 April 2016 Pukul 15: 08 